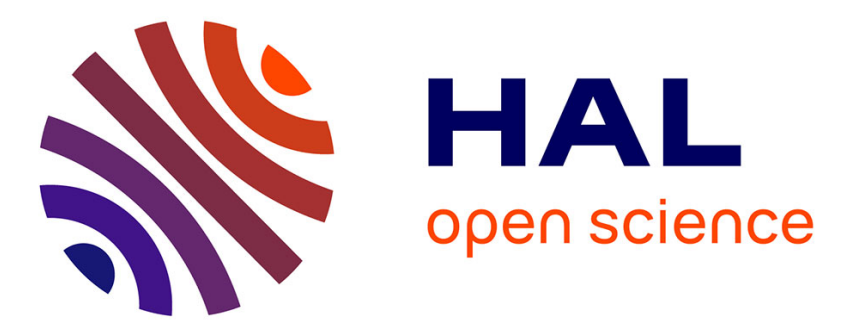

\title{
Effect of mesoscopic out-of-plane defect on the fatigue behavior of a GFRP
}

\author{
Christophe Cruanes, Anwar Shanwan, Stéphane Méo, Samir Allaoui, \\ Marie-Pierre Deffarges, Florian Lacroix, Gilles Hivet
}

\section{To cite this version:}

Christophe Cruanes, Anwar Shanwan, Stéphane Méo, Samir Allaoui, Marie-Pierre Deffarges, et al.. Effect of mesoscopic out-of-plane defect on the fatigue behavior of a GFRP. Mechanics of Materials, 2018, 117, pp.214-224. 10.1016/j.mechmat.2017.11.008 . hal-01648578

\section{HAL Id: hal-01648578 https://hal.science/hal-01648578}

Submitted on 5 Sep 2021

HAL is a multi-disciplinary open access archive for the deposit and dissemination of scientific research documents, whether they are published or not. The documents may come from teaching and research institutions in France or abroad, or from public or private research centers.
L'archive ouverte pluridisciplinaire HAL, est destinée au dépôt et à la diffusion de documents scientifiques de niveau recherche, publiés ou non, émanant des établissements d'enseignement et de recherche français ou étrangers, des laboratoires publics ou privés. 


\title{
Effect of mesoscopic out-of-plane defect on the fatigue behavior of a GFRP
}

\author{
C. Cruanes ${ }^{1 a}$, A. Shanwan ${ }^{b}$, S. Méo ${ }^{a}$, S. Allaoui ${ }^{b}$, M.-P. Deffarges ${ }^{a}$, F. Lacroix ${ }^{a}$, G. Hivet ${ }^{\text {, }}$ \\ a Université de Tours, LMR, Tours, F-37200, France \\ ${ }^{b}$ Université d'Orléans, PRISME, Orléans, F-45072, France
}

\begin{abstract}
This paper deals with the influence of buckles, a mesoscopic out-of-plane defect, on the fatigue behavior of a GFRP. Three cases were investigated: samples with no defect and two kinds of samples with buckle defects generated in the longitudinal or the transverse direction. Firstly, static tests were used to measure the differences in the mechanical properties of the two defect orientations and determine where the areas of maximum local strain were located. Secondly, fatigue tests were performed in the three configurations. The results revealed that both defect orientations have a significant effect on the fatigue behavior. The configuration with defects in the transverse direction was the most crippling condition but the longitudinal configuration was also strongly affected by the presence of mesoscopic defects. It was concluded that this mesoscopic out-of-plane defect has a major negative influence on the fatigue life of such a composite.
\end{abstract}

\section{Keywords}

Defect; Process; Fatigue; Forming; Glass fibers

\section{Introduction}

Composite materials are widely used in industry thanks to their very good mechanical properties for a lower mass than metal alloys. However, the processes developed in order to create the parts are complex and can induce defects, especially during textile forming, which will then impact the mechanical behavior.

These defects can be divided in two groups: macroscopic and mesoscopic (Figure 1). Macroscopic defects appear at the fabric scale. The most common and widely studied macroscopic defect is wrinkles. They are highly dependent on the fabric behavior and the boundary conditions. Initial studies limited the relationship between the limits of mechanical behavior reached during the process and wrinkles to the link between the in-plane shear behavior and the defect. Studies focusing on the shear angle reached during the process compared to the locking angle described this relationship (Wang et al., 1999; Potluri et al., 2001; Prodromou \& Chen, 1997; Sharma et al., 2003). Recent numerical studies (Hamila \& Boisse, 2008; Allaoui et al., 2011; Ten Thije et al., 2007) showed however that, as it is an out-of-plane phenomenon, the bending behavior of the membrane should be taken into account in order to correctly describe the shape and size of the wrinkles. A coupling between shear and tension has been highlighted in several papers (Boisse et al., 2011; Wilems et al., 2008; Allaoui et al., 2014) and wrinkles can therefore be avoided or delayed by applying tension along the yarn's network. Besides, wrinkles are the consequence of all the strains and rigidities of the fabric and of the boundary conditions (Allaoui et al., 2014). Wrinkle defects generate an over-thickness that impacts the geometrical tolerance and the aesthetics of the final part. Furthermore, studies have shown that this defect leads to a significant decrease in the

\footnotetext{
${ }^{1}$ Corresponding author: C. Cruanes, Université de Tours, LMR-CERMEL, 27 rue des martyrs, 37300 Joué-lès-

Tours, France. Email : Christophe.cruanes@univ-tours.fr.
} 
composite performance, with up to $40 \%$ loss of failure strength (Bloom et al., 2013; Hallander et al., 2013; Potter et al., 2008).

The second kind of defect, mesoscopic defects, appears at the yarn level. Examples are fiber and/or yarn breakage, "buckles", "weave pattern heterogeneity", "yarn waviness", etc. Some of them were only recently identified since, except for some work on the phenomena involved during the appearance of defects such as "yarn waviness", "buckles" and "weave pattern heterogeneity", few studies have dealt with mesoscopic defects (Allaoui et al., 2014; Lightfoot et al., 2013; Härtel \& Middendorf, 2013; Gatouillat et al., 2013). To the best of our knowledge, apart from a few studies on the effect of fiber waviness on UD composites (Hsiao \& Daniel, 1996; Piggott, 1995; Wang et al., 2012), the literature on the effect of mesoscopic defects is sparse (Allaoui et al., 2015b). However, it has been shown that they occur more often during the shaping of complex preforms (Allaoui et al., 2011; Ten Thije et al., 2007; Boisse et al., 2011; Wilems et al., 2008; Allaoui et al., 2014). In addition, inter-ply sliding significantly increases the amount and size of these defects when multilayered composite shaping is concerned (Allaoui et al., 2015a), hence the need to understand the phenomena involved and their criticality on the obtained composite.

Most of the literature on the impact of defects on mechanical behavior focuses on static tests. However, since the late 2000s, their influence on the fatigue behavior has begun to be investigated. It was observed for example that a ply drop increased the likelihood of the appearance of delamination (Helmy \& Hoa, 2014; Thawre et al., 2016). Moreover, (Reis et al., 2009; Colombo \& Vergani, 2014) pointed out that that the presence of a defect inducing delamination was difficult to detect in static tests despite dramatically decreasing the fatigue life.

The present study aims to assess the effect of the "buckle" defect on the mechanical properties of a composite and specifically its fatigue behavior. To this end, "buckles" were generated on a dry fabric layer taking care to reproduce the amplitudes observed on a complex composite part (Figure 1). Composite plates, stacked in layers with the same orientation, were then fabricated by injecting epoxy resin using a resin transfer molding device. Plates without defects were also fabricated to be used as a reference. Uniaxial tensile tests and fatigue tests instrumented with digital image correlation devices were then performed. The results of these different configurations were compared in order to evaluate the effect of "buckles" on the fatigue behavior of the composite.
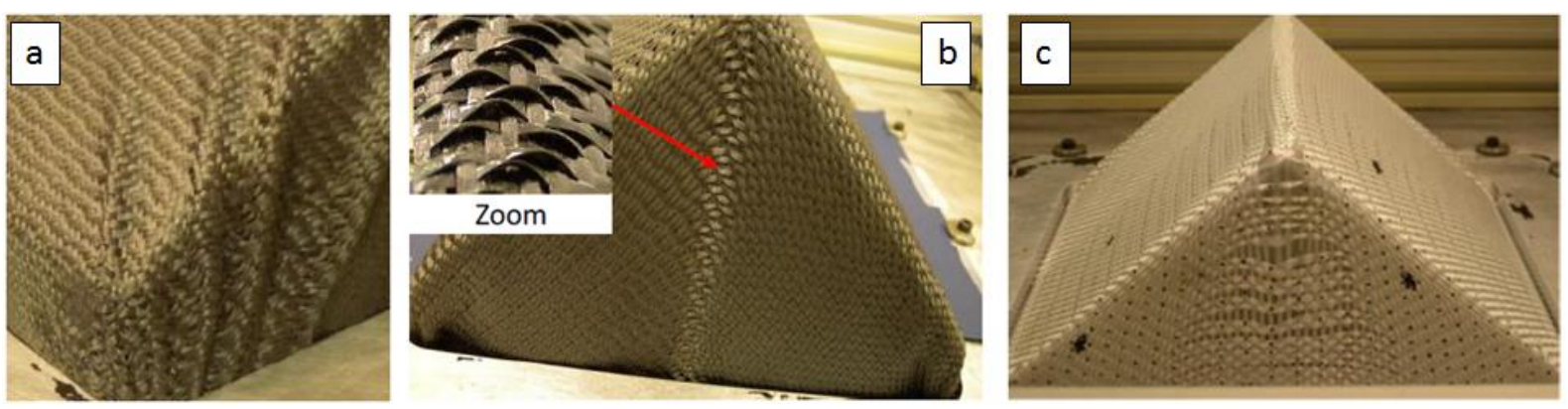

Figure 1 - Defects observed on a double curved shape: (a) macroscopic (wrinkles), (b) mesoscopic ("buckles") and (c) mesoscopic ("weave pattern heterogeneity") - from (Allaoui et al., 2015b)

\section{Material and specimen preparation}

\subsection{Material}

The material used in this study is a glass fiber reinforced polymer. The Resin Transfer Molding process was used to produce composite plates, with and without defects. The fabric used is a glass plain weave produced by Chomarat. It is denoted G-WEAVE 600P and has the following properties: a real weight of $600 \mathrm{~g} / \mathrm{m} 2 \pm 5 \%$, thickness of $0.55 \mathrm{~mm}$, warp and weft yarns count of 600 Tex. 
Thermoset epoxy resin LY564 ARALDITE with a suitable hardener 3487 ARADUR was used to inject the stacks performed according to the protocol described below. The fabric is balanced which was confirmed following DMA measurements performed on the GFRP which showed that the mechanical characteristics were similar along the warp and weft orientations.

\subsection{Sample preparation}

In order to produce plates without defects, the reinforcement was cut into square samples of $250 \times 250 \mathrm{~mm}^{2}$. These dimensions were selected to fit the size of the mold. For plates with buckle defects, the reinforcement was cut into square samples of $500 \times 500 \mathrm{~mm}^{2}$. Then, the sample was placed on a machine equipped with four automated portal axes which can be commanded separately or simultaneously. Buckle defects were generated by applying a defined driving mode in the machine program. The sample was clamped on the machine upon its three sides $\left(X, X^{\prime}\right.$ and $Y$, Figure 2), then, a displacement at a constant velocity was applied on the $Y$ side ( $y$ axis) while the opposite side $\left(Y^{\prime}\right)$ remained free. Simultaneously, the other two sides, $X$ and $X^{\prime}$, were piloted according to a force control order. As a result, the two sides move towards the center of the sample. Thanks to this type of control order, the reinforcement sample stretches in the $Y$ direction and shrinks in the $X$ and $X^{\prime}$ directions. After reaching the required amplitude of defects, the sample is kept fixed and a fixing agent is sprayed on the surface of the sample. When the sprayed layer has dried, the calibrated sample can be removed and then cut into a square of $250 \times 250 \mathrm{~mm}^{2}$, as shown in Figure 2.

Several plies with calibrated defects were produced according to this protocol, and a stack of 7 plies oriented in the same direction was placed in the RTM mold. Then, the epoxy matrix was injected and the mold transferred into an oven preheated at $100^{\circ} \mathrm{C}$. After 3 hours, the mold was removed and allowed to cool at ambient temperature for 6 hours. The final thickness of the composite plates was about $2.5 \mathrm{~mm}$. Lastly, these plates were cut into several samples for the mechanical tests.

The samples used for the tests were all designed following the ISO 527-4 1B standard (Figure 3) allowing the use of lower capacity load cells and the localization of the damage in a central area of the sample, away from the clamps. They were cut out by waterjet cutting.

In the paper, the three configurations of samples for the mechanical tests will be named as follows (Figure 4 and Figure 5):

No defect samples, or "ND", cut from the reference plates without defects and which will be taken as the reference (Figure 5 -a).

Longitudinal defect samples, or "LD", cut along the area of the plates containing the calibrated buckle defects. The defect is placed on the central axis along the sample (Figure 5-b).

Transverse defect samples, or "TD", cut in the transverse direction of the plates with calibrated defects. The buckles are oriented at $90^{\circ}$ with respect to the central axis of the sample (Figure 5-c) and are present only locally in an area on the center of the sample. 


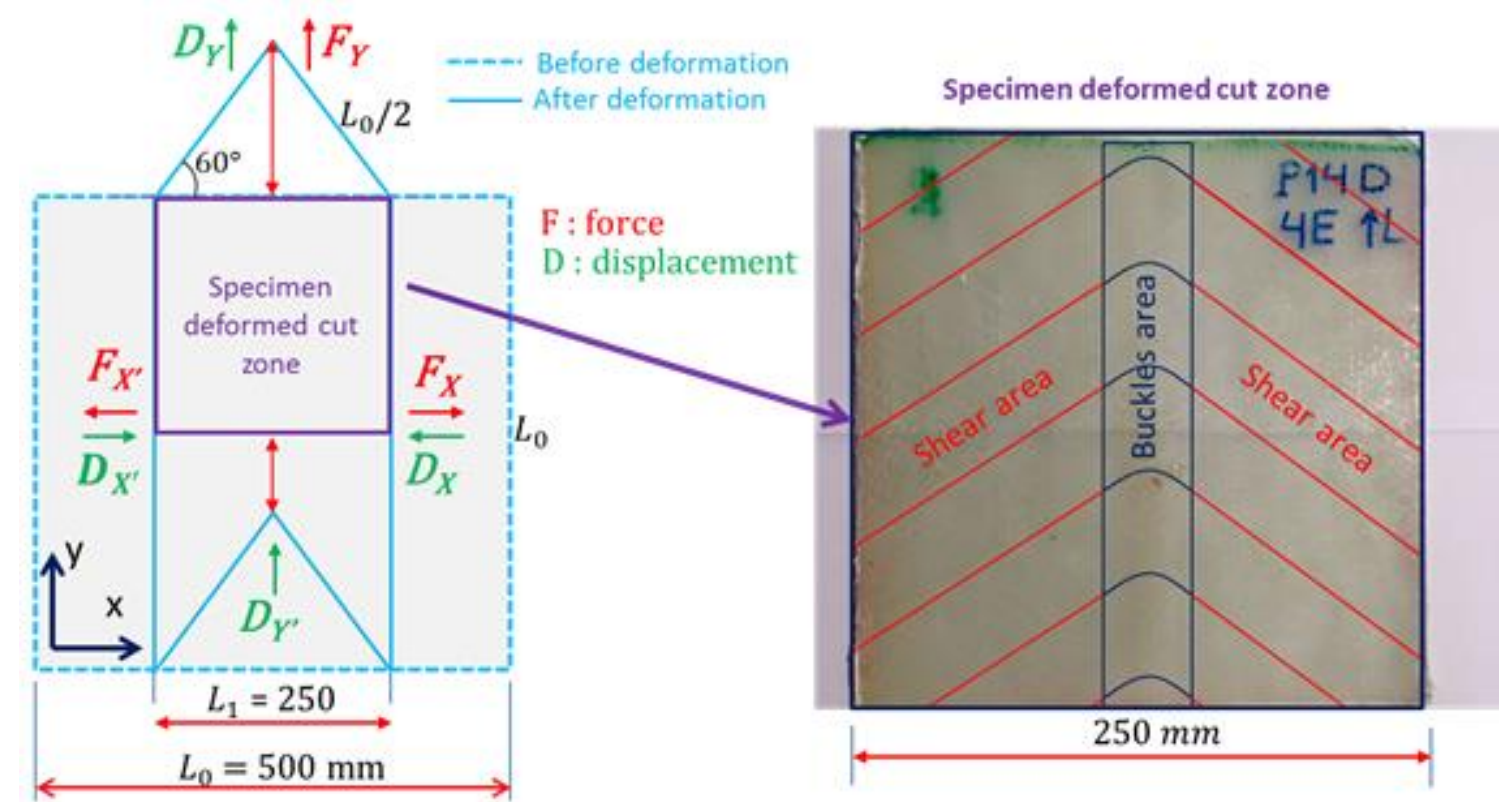

Figure 2 : Example for buckle defects generation

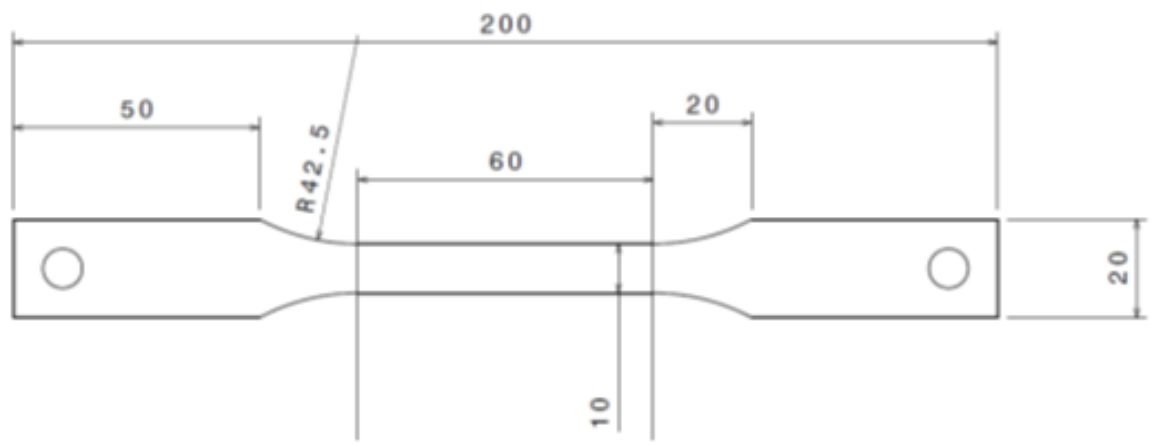

Figure 3 - Shape of the sample according to the ISO 527-4 1B (the dimensions are in $\mathrm{mm}$ ). Thickness: $2.5 \mathrm{~mm}$

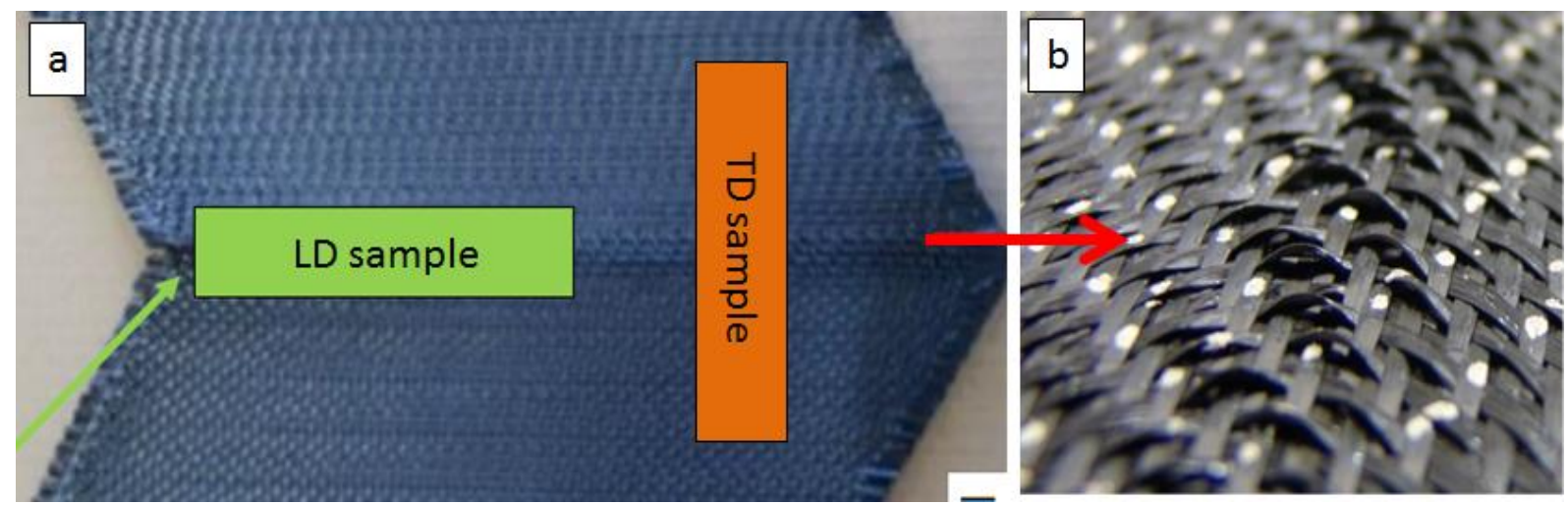

Figure 4 - (a) orientation of the cut of the LD and TD samples on the plate presenting a buckle defect. (b) zoom on the buckle defect. From (Allaoui et al., 2015b). 


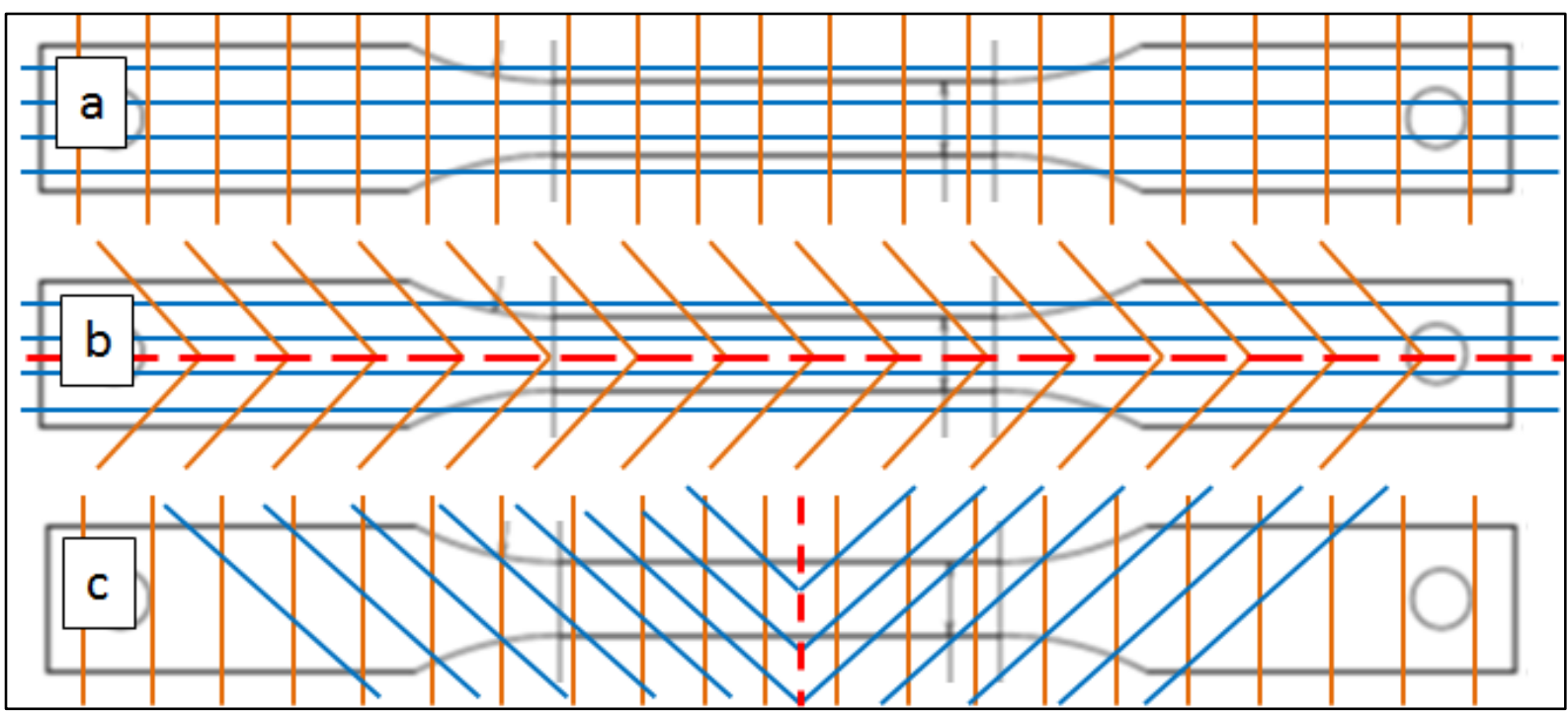

Figure 5 - Superposition of the grid of yarn on the sample in the three configurations: (a) ND, (b) LD and (c) TD. The thick red dotted line stands for the location of the buckle defect.

\section{Experimental protocol}

In order to investigate the effect of the buckle defect and its orientation on the mechanical behavior of the GFRP, static and fatigue tests were performed. They were both conducted on an Instron 8872 servo-hydraulic fatigue testing machine at room temperature.

\subsection{Digital Image Correlation}

(Bloom et al. 2013) showed that the impact of a ply defect could be monitored with a Digital Image Correlation (DIC) device. Therefore, in order to record the strain field and its evolution during the tests investigated in this paper, a DIC system composed of two 5-million-pixel CCD cameras (2448x2048 pixels) and the ARAMIS acquisition software was used. The samples were prepared by firstly a layer of white paint and secondly a random pattern of dots with black paint in order to have a contrasted surface facing the cameras.

\subsection{Static tests}

The static tests were displacement controlled at $2 \mathrm{~mm} / \mathrm{min}$. The loading cells used had a capacity of $25 \mathrm{kN}(+/-125 \mathrm{~N})$ for the ND and LD samples and $5 \mathrm{kN}(+/-25 \mathrm{~N})$ for the TD. The sampling used was $100 \mathrm{~Hz}$. The samples are griped on the machine as shown on the Figure 6.

The acquisition frequency of the DIC for the static tests was $1 \mathrm{~Hz}$. 


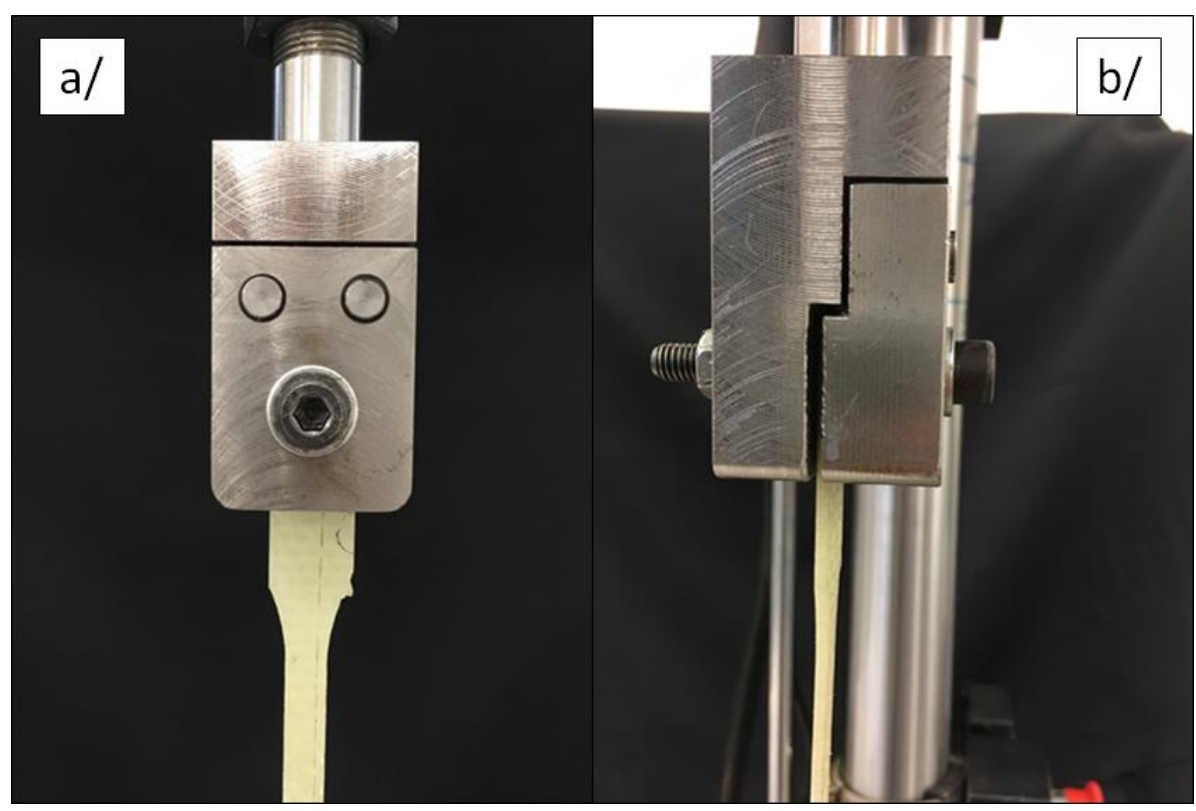

Figure 6 - Front view (a/) and side view (b/) of the fixation of the sample on the machine.

\subsection{Fatigue tests}

The fatigue tests were carried out on the same machine as for the static tests, with the same loading cells. The tests were stress controlled, uniaxially, at $5 \mathrm{~Hz}$ and with a 0.1 load ratio (defined as the ratio between the lowest and highest stress undergone by the sample during a cycle $\sigma_{\min } / \sigma_{\max }$ ) to ensure that the samples would not undergo buckling.

Table 1 shows the stresses investigated for the three types of samples. The tests were carried out until failure of the sample and were chosen to cover from $50 \%$ of the ultimate stress $\sigma_{u}$, measured during the static test, to $25 \%$ of $\sigma_{u}$ for the ND samples. For the other two types of samples, the tests also started at $50 \%$ of $\sigma_{u}$ and then the maximum strain was steadily decreased based on the fatigue life of previous stresses. The lowest stress at which failure of the sample occurred was at $40 \%$ of $\sigma_{u}$ for the TD and $25 \%$ of $\sigma_{u}$ for the LD. A test was carried out at $25 \%$ of $\sigma_{u}$ for the TD but was stopped after almost 12 million cycles without showing any sign of change in its fatigue behavior.

Because of the high stiffness of the samples, the global strain measured directly on the fatigue machine through the displacement of the actuator needed to take the compliance of the machine into account. It was decided to use the DIC measurement to measure the actual global strain, by measuring the displacement of two points placed outside the central area at the top and bottom part of the sample. However, the DIC measurement had to be carried out every 10 or 20 minutes (depending on the test) because of the size of the files whereas the fatigue machine was able to measure the global strain every cycle. A ratio was therefore calculated between the global strains measured with the DIC and the fatigue machine. This ratio appeared to be constant during the fatigue test until the onset of sample failure. Applying this ratio to the global strain measured by the fatigue machine gave the actual global strain which will be used in the remainder of the article.

Each DIC measurement lasted 30 seconds, or 150 cycles. The software recorded one image every $0.39 \mathrm{~s}$, or every 1.95 cycles, resulting in the recording of 75 images. This allowed the smoothing of the evolution of the results should there be a cycle where a punctual perturbation occurred. The strain values were therefore measured at a number of cycles taken as the middle value in the interval of cycles during which the measurement was conducted. 


\begin{tabular}{|c|c|c|c|c|}
\hline & $\begin{array}{l}\text { Maximum effort } \\
F_{\max }(\mathrm{kN})\end{array}$ & $\begin{array}{c}\text { Maximum global stress } \\
\sigma_{\max }(\mathrm{MPa})\end{array}$ & $\begin{array}{l}\text { Maximum global normalized } \\
\text { stress } \frac{\sigma_{\max }}{\sigma_{u l t}}\end{array}$ & $\begin{array}{l}\text { Fatigue life } N_{r} \\
\quad \text { (cycles) }\end{array}$ \\
\hline \multirow{9}{*}{ 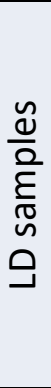 } & 5 & 193.80 & 0.50 & 1250 \\
\hline & 3 & 111.11 & 0.30 & 9763 \\
\hline & 2.75 & 104.56 & 0.28 & 15734 \\
\hline & 2.5 & 88.34 & 0.25 & 30713 \\
\hline & 2.25 & 82.42 & 0.23 & 55402 \\
\hline & 2 & 73.53 & 0.20 & 302000 \\
\hline & 1.8 & 70.87 & 0.18 & 1035560 \\
\hline & 1.6 & 62.99 & 0.16 & 20000 \\
\hline & 1.25 & 46.30 & 0.13 & 4700000 \\
\hline \multirow{20}{*}{ 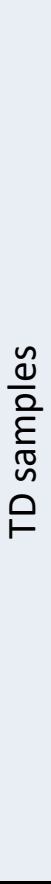 } & 0.25 & 9.96 & 0.31 & $>11680000$ \\
\hline & 0.375 & 14.82 & 0.46 & 77400 \\
\hline & 0.375 & 14.94 & 0.47 & $>2900000$ \\
\hline & 0.375 & 14.76 & 0.46 & 103539 \\
\hline & 0.375 & 14.76 & 0.46 & 1029370 \\
\hline & 0.375 & 15.12 & 0.47 & 954000 \\
\hline & 0.4 & 16.13 & 0.51 & 222000 \\
\hline & 0.4 & 15.59 & 0.49 & 43200 \\
\hline & 0.4 & 15.94 & 0.50 & 52300 \\
\hline & 0.4 & 16.13 & 0.51 & 895000 \\
\hline & 0.4 & 15.33 & 0.48 & 13375 \\
\hline & 0.45 & 18.07 & 0.57 & 95221 \\
\hline & 0.45 & 17.51 & 0.55 & 12000 \\
\hline & 0.45 & 18.99 & 0.60 & 25000 \\
\hline & 0.45 & 18.07 & 0.57 & 546000 \\
\hline & 0.5 & 20.41 & 0.64 & 139200 \\
\hline & 0.5 & 20.33 & 0.64 & 18038 \\
\hline & 0.5 & 19.46 & 0.61 & 12000 \\
\hline & 0.5 & 20.62 & 0.65 & 13700 \\
\hline & 0.5 & 20.16 & 0.63 & 17800 \\
\hline \multirow{9}{*}{ 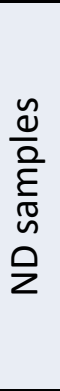 } & 6 & 220.59 & 0.49 & 8000 \\
\hline & 5 & 190.84 & 0.42 & 14000 \\
\hline & 4 & 151.52 & 0.34 & 86000 \\
\hline & 4.5 & 163.64 & 0.36 & 41027 \\
\hline & 4.5 & 163.64 & 0.36 & 48000 \\
\hline & 3.5 & 132.08 & 0.29 & 277168 \\
\hline & 3.35 & 127.38 & 0.28 & 1693820 \\
\hline & 3.25 & 116.91 & 0.26 & 2077000 \\
\hline & 3 & 112.78 & 0.25 & 3279000 \\
\hline
\end{tabular}

Table 1 - List of the stresses investigated in fatigue depending on the type of defect and the associated fatigue life. If the latter is in red, it means that the test was stopped before failure.

\section{Results}

\subsection{Static tests}

The first step was to carry out static tests in order to estimate the ultimate stress on one sample for each configuration and also to locate the areas of maximum strain thanks to the digital image correlation (DIC) measurements. This information is useful for the fatigue part.

\subsubsection{Mechanical response}

The evolution of the stress versus the strain during the static test for the three conditions is given on Figure 7. 
It can be observed that the evolution, moduli and ultimate stresses of the ND and LD samples were very similar. (Allaoui et al., 2015b) found that the LD samples had even better mechanical characteristics than ND samples and attributed this result to the stiffness contribution of the transverse yarns, which, on undergoing the out-of-plane defect, are no longer perpendicular with respect to the loading axis as shown on Figure 5. This may be due to the rotation angle of the transverse yarns over the specimen width which can be very small in our case, thus inducing a zero contribution of rigidity. This variation is caused by the difference in the meso-architecture of the materials used in the two studies and their mechanical behavior. In addition, the difference here is that only one static test was performed for each configuration. It is therefore not possible to tell whether there is an increase or decrease in the mechanical properties. Therefore, and as the present study focuses more on the fatigue aspects, it will be considered in the rest of the paper that the longitudinal orientation of the defect does not clearly impact the static characteristics of this GFRP.

The ND and LD also showed some damage in the area at the limit of the operational area of the sample, where the width goes from 10 to $20 \mathrm{~mm}$. This is an issue already observed (Garcea et al., 2014; Garcea et al., 2015, for example), but it was not met during the fatigue tests.

However, the TD sample differed greatly, exhibiting much lower mechanical properties. This is again due to the presence of defects and to the fact that there are no yarns oriented in the loading direction as these yarns are those which are submitted to out-of-plane buckling and consequently they rotate on the areas adjacent to the defects (sees Figure 5). All of these phenomena seem to cause a global weakening of the sample.

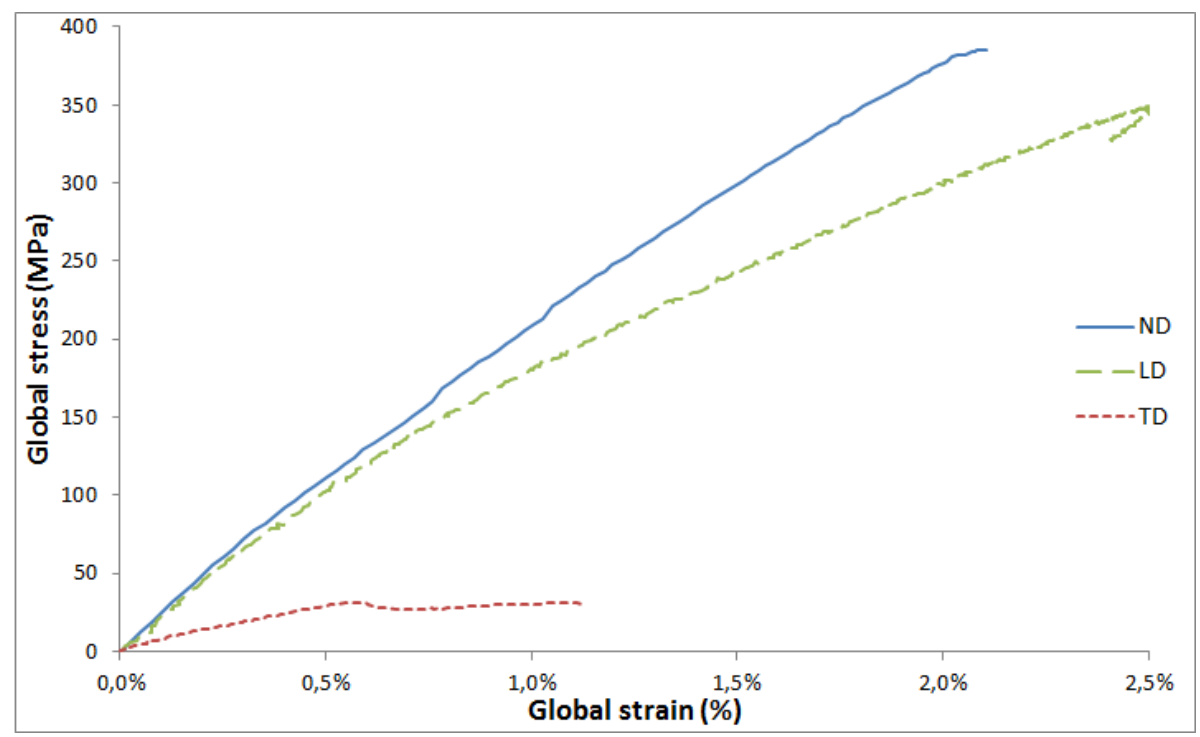

Figure 7 - Evolution of the stress versus the strain for the ND, LD and TD samples (1 test per curve)

\subsubsection{DIC measurements}

Figure 8-9 show where the areas of maximum strain are located on each sample. It should be noted that the local strain measured by the DIC can be the consequence of both the mechanical response of the material and the opening of a nearby crack. The absolute values, on the profiles for example, need therefore to be carefully considered when a crack has been observed.

The ND sample showed that most of the areas of maximum strain are randomly dispatched in the central area of the sample. Many high local strain areas can be observed (Figure 8). The higher variations of strain (in yellow) were most probably caused by the plasticization of the matrix induced by the pattern of the yarns in the plies. 
The LD sample showed many areas where the local strain is much higher than the global strain, with the most intense local strain on the sides of the sample (Figure 9). It seems that in these side areas (which are crossed by paths 1 and 3 ) the local strain increased much faster than in the central area (even if in the latter it can reach 3 times the global strain) since it is in these side areas that cracks can be seen, despite the fact that this is supposedly still the elastic phase of the test. With the LD configuration, the mechanical properties remained close to those of the ND configuration at the cost of the presence of many cracks in the sample at an early stage.

The TD sample showed two areas where the local strain was much higher than the global strain (Figure 10). These areas were located in the vicinity of the defect, which was also the only place where cracks were encountered. The lower mechanical properties are well explained as the local strain in the areas is almost 20 times higher than the global strain on Figure 10-b.

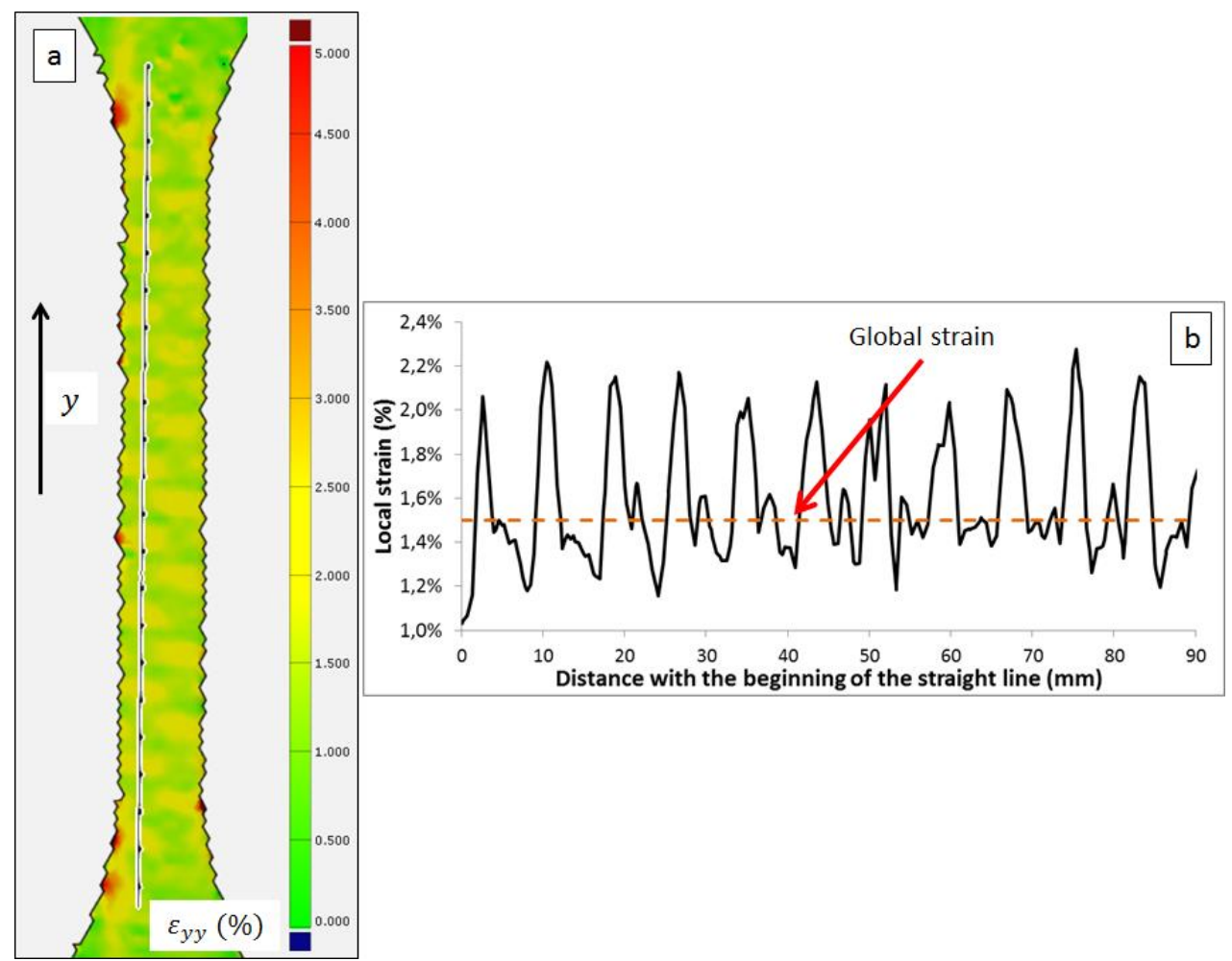

Figure 8 - ND sample: local strain field measured with DIC during the static test while the global strain is $1.5 \%$ (a). (b) shows the evolution of the local strain along the path depicted in figure (a). 


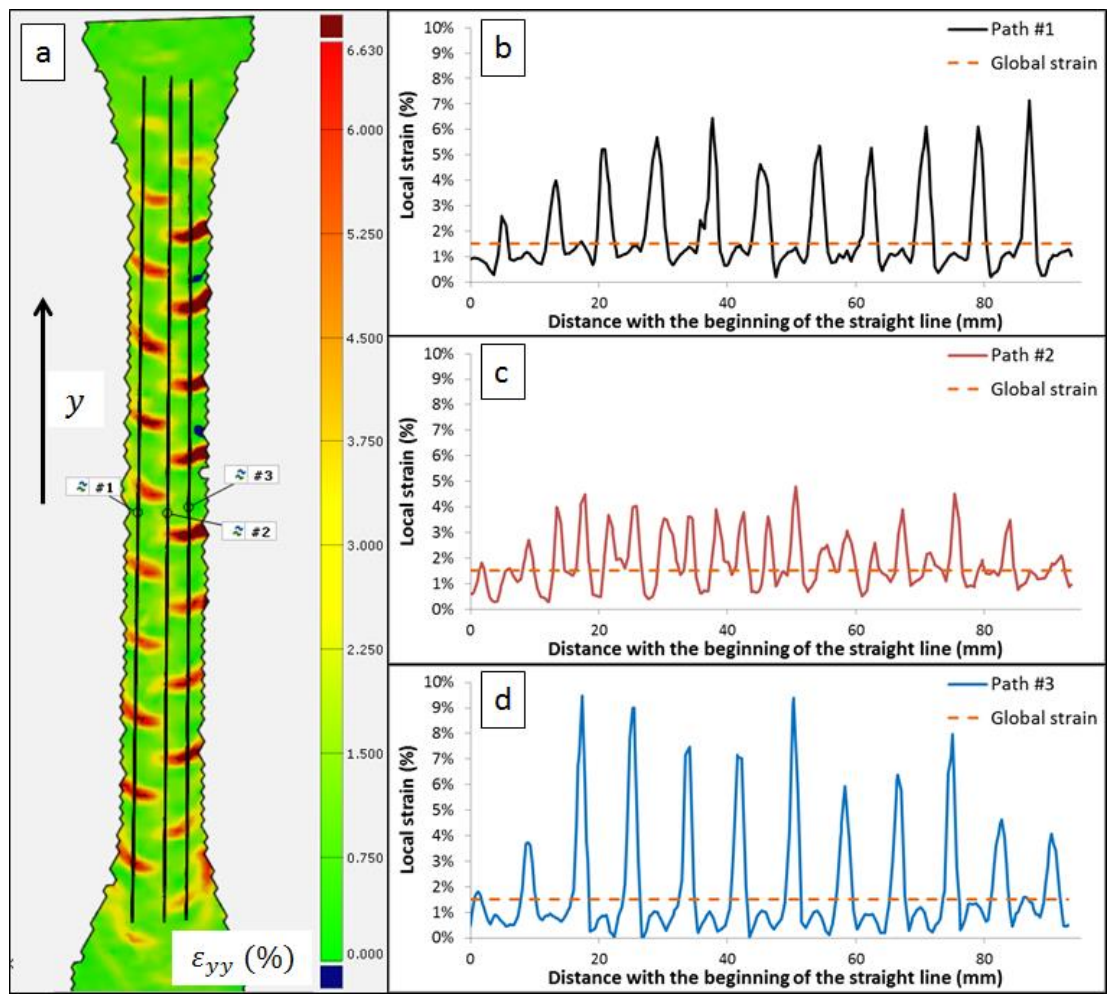

Figure 9- LD sample. Local strain field measured with DIC during the static test while the global strain is $1.5 \%$ (a). (b) (respectively (c) and (d)) shows the evolution of the local strain along path \#1 (resp. \#2 and \#3) in figure (a).

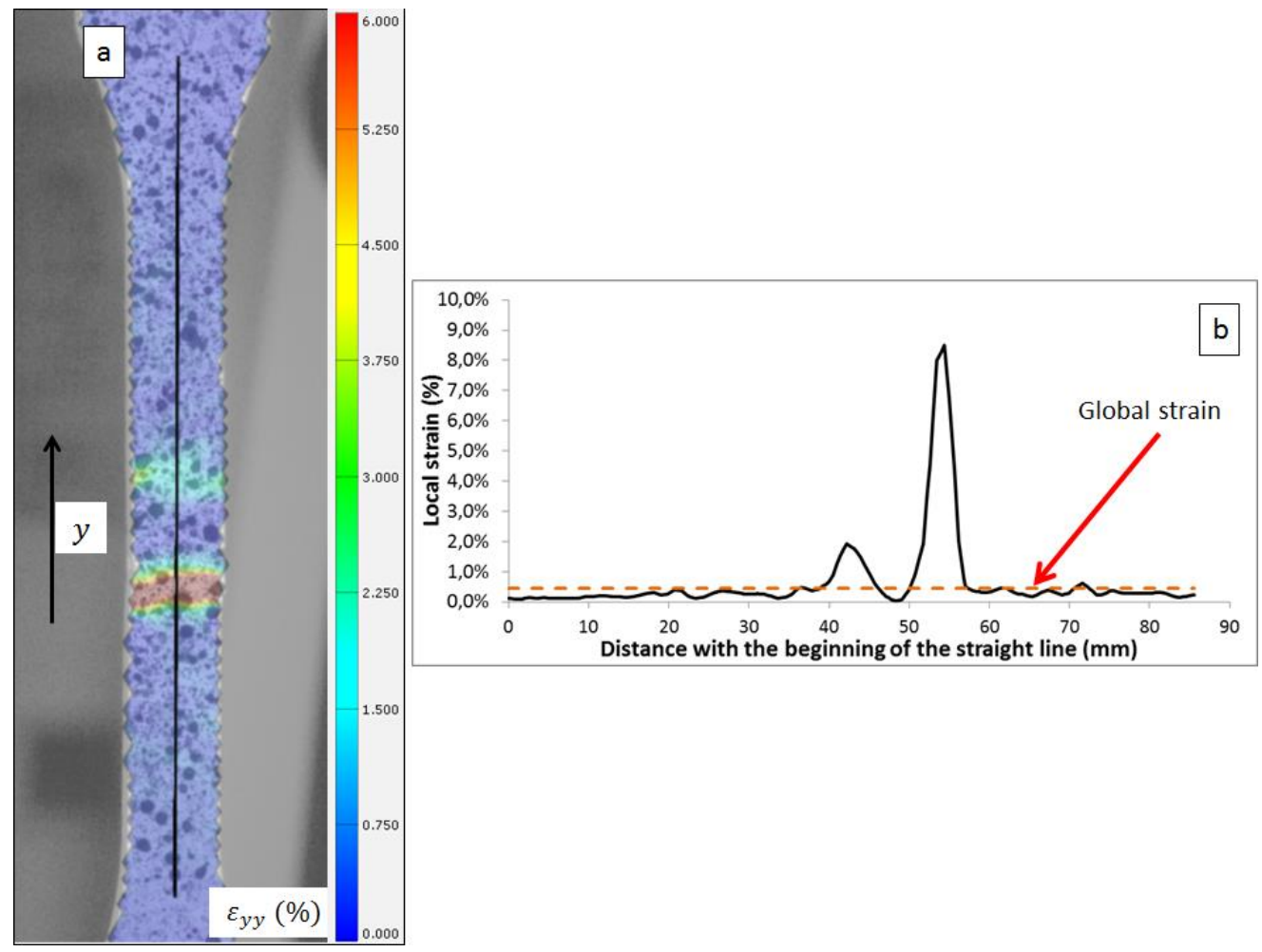

Figure 10 - TD sample: local strain field measured with DIC during the static test while the global strain is $0.46 \%$ (a). (b) shows the evolution of the local strain along the path depicted in figure (a). 


\subsection{Fatigue tests}

The static tests gave access for each type of sample to the ultimate stress and their capacity to produce an area of strain concentration where cracks would be most likely to occur.

\subsubsection{Wöhler curves}

The Wöhler curve for each sample is drawn on Figure 11. All the samples showed a classical evolution divided in two parts: low (LCF) and high cycle fatigue (HCF). The equation of the logarithmic evolution during the LCF phase is also plotted (dotted line). The two phases are differentiated by the type of damage the sample undergoes: static-fatigue damage is predominant during the LCF phase, whereas fatigue-fatigue damage is predominant during the HCF phase (Epaarchchi, 2006).

\subsubsection{ND samples}

For the ND samples, the limit between LCF and HCF was around $29 \%$ of the ultimate stress, at a stress of $132 \mathrm{MPa}$.

It can be seen on Figure 12 that the stiffness decreased during fatigue tests. Two phases can be identified: a slow decrease followed by a faster one until failure of the sample. The intensity of the first phase depends on the stress: the stronger the maximum stress, the steeper the slope. The reason for this first slow decrease is that the pattern followed by the yarns (taffeta) generates some local plasticization as seen on Figure 8, meaning that the matrix will creep. Then, at some point during the test, cracks appeared and propagated, accelerating the decrease in stiffness (Demers, 1998; Montesano et al., 2015; Naderi \& Khonsari, 2012).

The DIC observations showed that for the lower stresses, below the LCF/HCF limit, there are many areas where the local strain is many times higher than the global strain (see 3.1.2) as can be seen on Figure 13. These areas are most likely plasticized and will eventually lead to the appearance of surface cracks. For the higher stresses, there are fewer cracks ( 2 or 3 at the top) which initiated from one of the plasticized areas.

\subsubsection{TD samples}

The TD samples were expected to have the lowest fatigue characteristics among the three types of sample given the static tests. The limit between low and high cycle fatigue is close to $45 \%$ of the ultimate stress, at a stress of $14 \mathrm{MPa}$.

It can be seen that the areas of maximum strain are in the neighborhood of the defect, which is the same as in static tests. The DIC observations showed that the cracks initiated for all the samples in one of the two areas, which is logical as the maximum local strain measured is much higher than the global maximum strain recorded on a cycle. Figure 14 shows that for a test at $15 \mathrm{MPa}$ with a fatigue life of $10^{6}$ cycles, the ratio of the maximum local and global strain at the $510000^{\text {th }}$ cycle is around 16. It appears that for the TD samples, the average ratio is around 22.15.

The rest of the sample showed very little variation in the field of strain, which is expected as the stresses undergone by the TD samples are very low compared to those of the ND campaign (20MPa maximum versus $220 \mathrm{MPa}$ maximum).

\subsubsection{LD samples}

The fatigue characteristics of the LD samples were lower than those of ND with a LCF/HCF limit between $20 \%$ and $22 \%$ of the ultimate stress, at a stress around $78 \mathrm{MPa}$.

The areas of maximum strain, shown on Figure 15, can be divided in two groups. The first one is composed of areas located on the two edges of the sample, at the same sites of maximum strain as those observed in static tests (Figure 9). However, the sample failed before these fatigue areas 
reached a size comparable with the static ones. This is caused by the appearance of a second group of areas of maximum deformation positioned at the center of the sample surface. The areas of this second group are regularly distributed along the center axis of the sample, where the warp yarns form an angle (Figure 2). These observations correlate very well with the distinction between staticfatigue and fatigue-fatigue damage as already discussed in the literature (Helmy \& Hoa, 2014; Reifsnider, 1990; Phoenix, 2000; Beaumont \& Sekine, 2000).

\subsubsection{Comparisons between the ND samples and the defective samples}

Beforehand, we will introduce the LMS/GMS ratio. At the number of cycles where the stiffness starts to plummet (Figure 12), the Local and Global Maximum Strains (LMS and GMS) were measured, using the DIC, over this cycle and a LMS/GMS ratio was calculated (Table 2). A possible problem with the measurement of the LMS was that it is amplified by a nearby crack. If it is located ahead of the tip of a crack, there is no problem as the local strain is a mechanical response of the material to the presence of the crack. However, if the LMS was located in the crack, it was not taken into consideration.

- Comparison between ND and TD:

The fatigue behavior of the ND and TD samples was qualitatively different: the LCF/HCF limit of the TD samples was for a maximum stress leading to $1^{\prime} 000^{\prime} 000$ cycles, whereas for the ND samples it was around 200'000 cycles. The slope of the LCF line was lower for the TD than the ND (Figure 11).

The TD samples experienced a more localized damage than the ND samples. While the maximum stress and the maximum global strain were much lower for the TD samples, the local maximum strain was much higher: the LMS/GMS ratio was between 11.53 and 32.94 for the TD (average value of 22.15) whereas it was between 3.79 and 17.33 for the ND (average value of 8.06) (Table 2). It is also interesting to note that the LCF/HCF limit increased from 0.29. $\sigma_{u}$ (ND) to 0.45. $\sigma_{u}$ (TD).

The presence and the orientation of the defects have a substantial influence on the mechanical properties, whether static or fatigue, causing the yarns to be less efficient and the matrix to work more than in the normal configuration.

- Comparison between ND and LD:

They both had the same fatigue behavior, with a LCF/HCF limit for a maximum stress leading to a fatigue life of around 200 '000 cycles. Moreover, the slope of the LCF line was roughly the same (Figure 11).

However, the LD samples underwent more damage than the NDs. For a test at 111.1MPa, the fatigue life was $3.1 .10^{6}$ cycles for the ND whereas it was $10^{4}$ cycles for the LD. It also appeared from the DIC observations that the yarn network in the LD induced plasticization and eventually damage in the sample as the LMS/GMS ratio was much higher: from 5.54 to 16.75 for the LD (average value of 11.54) compared to a range from 3 to 17 for the ND (average value of 8.06) (Table 2).

The presence of buckle defects in the LD configuration creates a source of delamination around the central axis of the sample which was more pronounced than on the ND samples (Figure 16).

It is worth noting that while the presence of the defect with this orientation has a great impact on the static behavior (Allaoui et al. 2015b), it has a major effect on the fatigue behavior (Epaarchchi, 2006; Demers, 1998) by enabling delamination in the sample. This explains the differences between the behaviors of the two types of samples (Dyer et Isaac, 1998). 

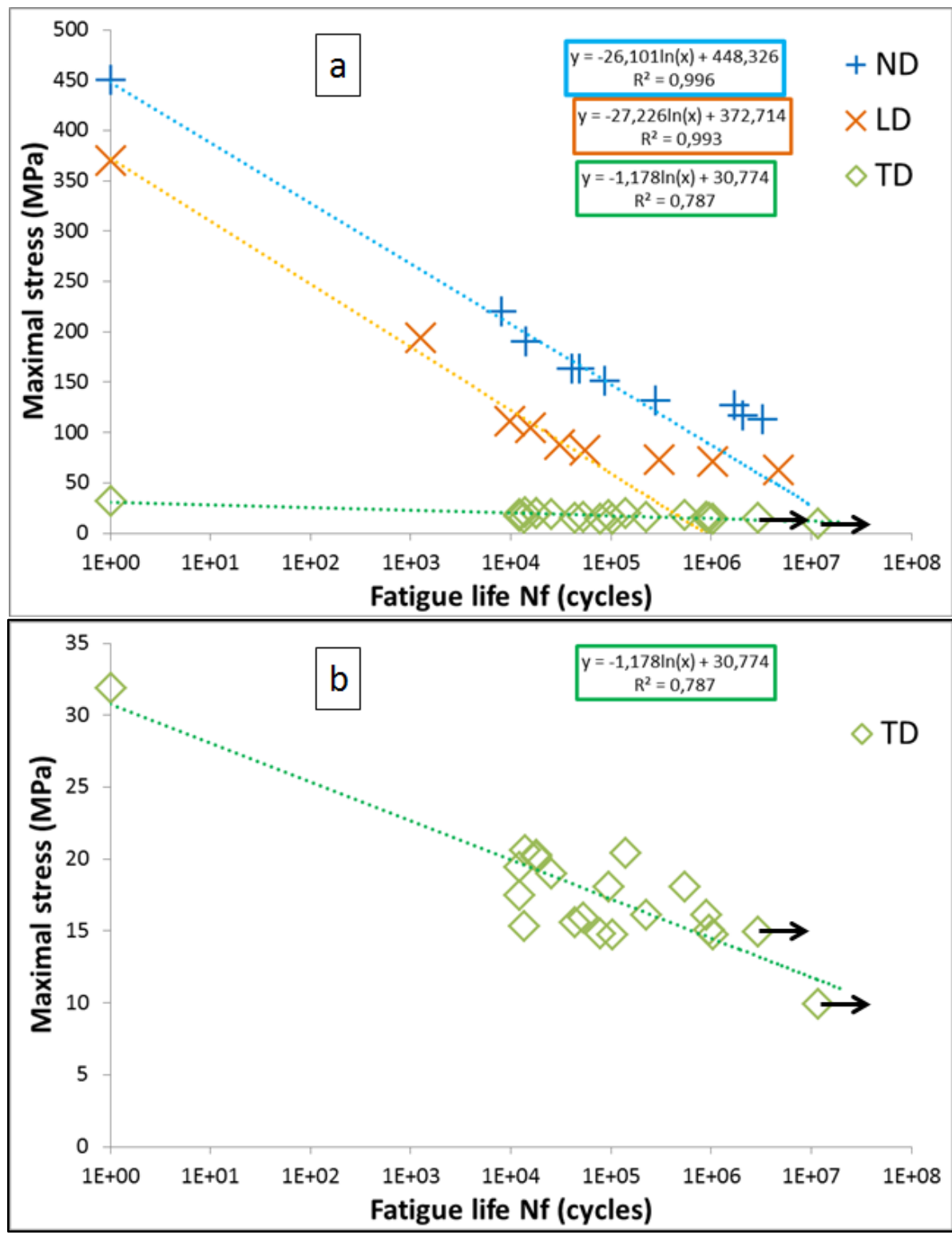

Figure 11 - Wöhler curve for each sample in a maximum stress/fatigue life chart (a). Chart (b) shows a zoom on the TD Wöhler curve. The dotted lines represent the fatigue behavior during the LCF phase. 


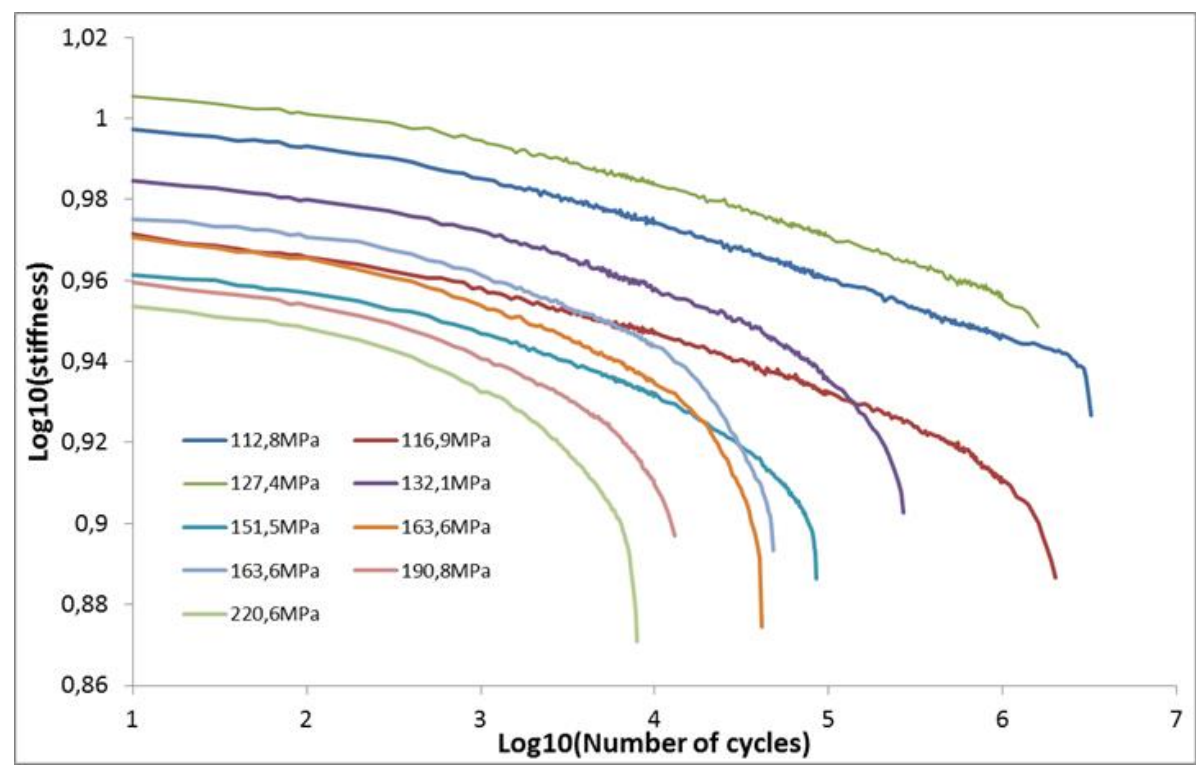

Figure 12 - Evolution of stiffness during the fatigue tests on the ND samples in a log/log chart.

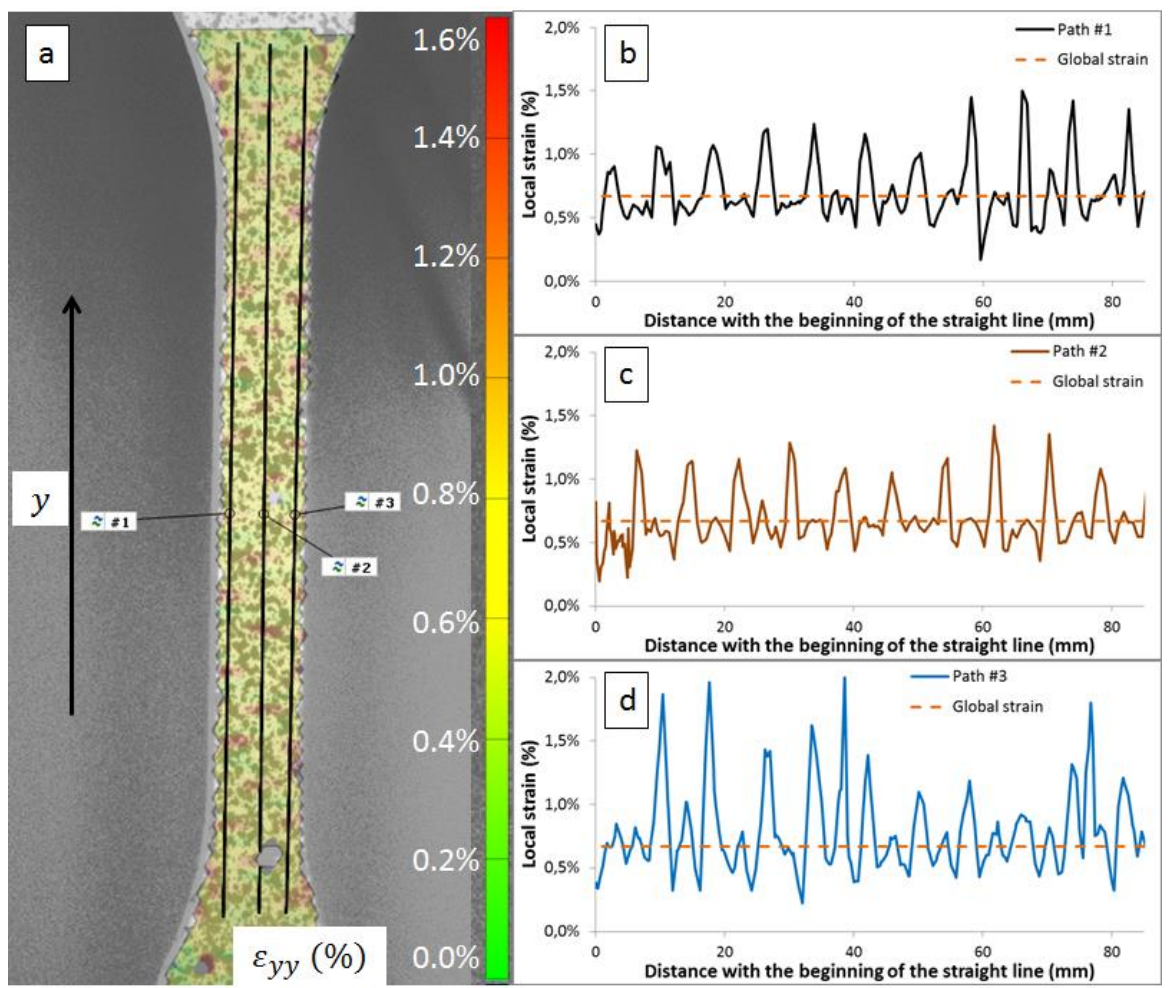

Figure 13 - (a) Example of strain distribution on a ND sample during a fatigue test ( $\sigma_{\max }=$ $127,4 \mathrm{MPa}, N=510000$ cycles, $\varepsilon_{\text {glob }}=0,67 \%$ ). (b), (c) and (d) show the evolution of the local strain along paths \#1, \#2 and \#3. 


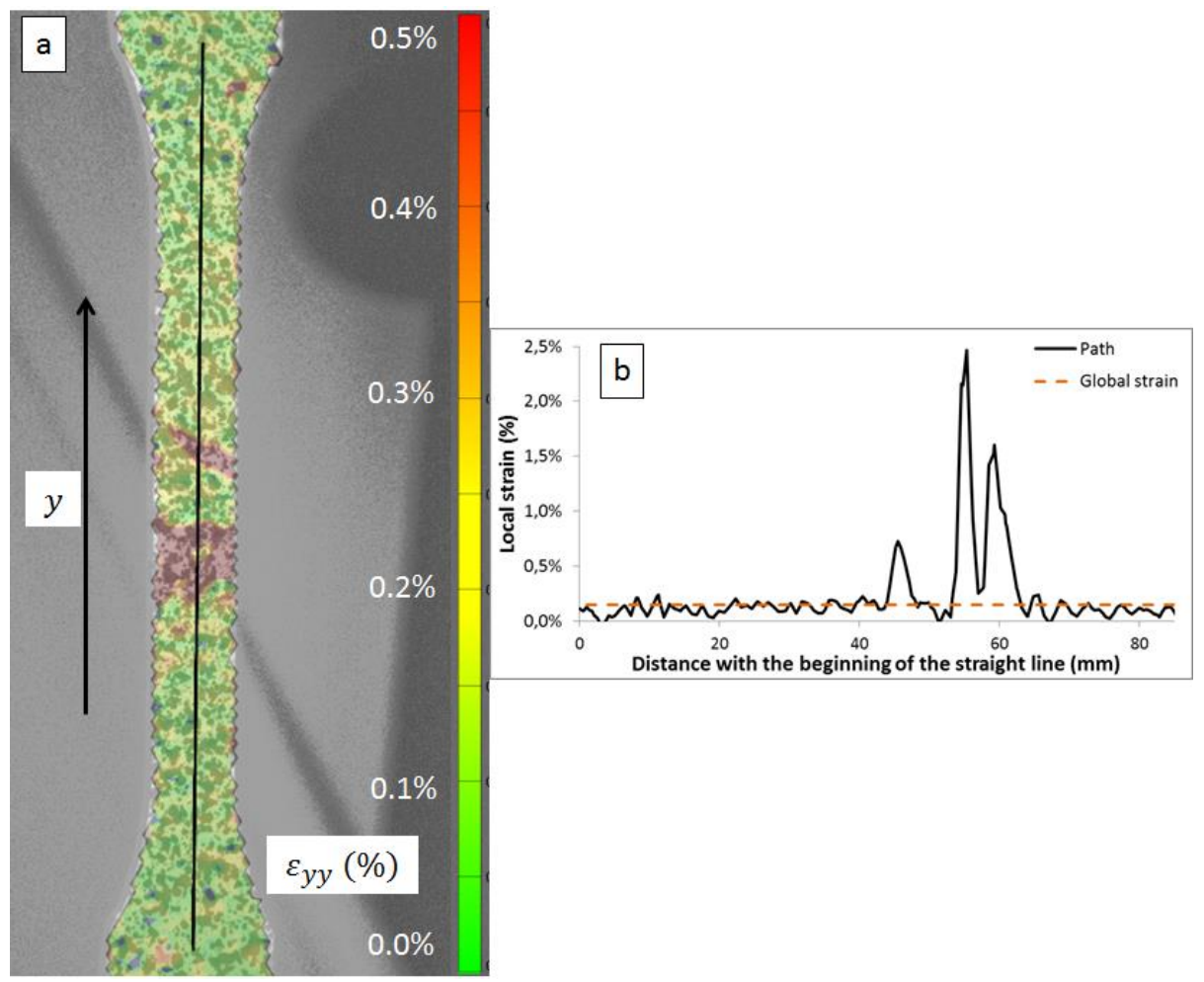

Figure 14 - (a) Measurements of the local and global maximum strain on a TD sample $\left(\sigma_{\max }=\right.$ $15 \mathrm{MPa}, N=510000$ cycles, $\varepsilon_{\text {glob }}=0,15 \%$ ). (b) shows the evolution of the local strain along the path depicted on figure (a).

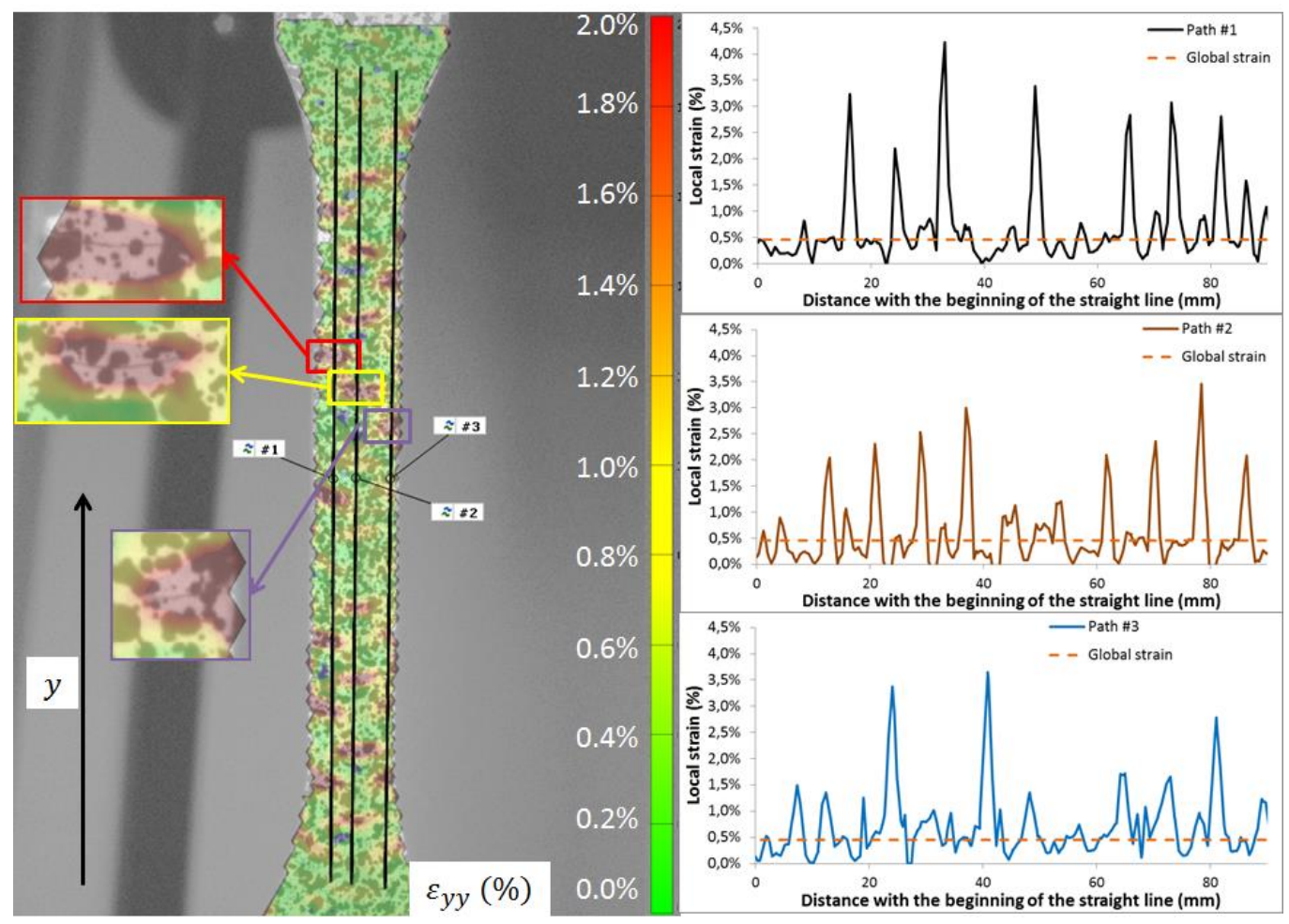

Figure $15-\left(\right.$ a) DIC measurements of the local strain on a LD sample $\left(\sigma_{\max }=70,9 \mathrm{MPa}, N=\right.$ 620000 cycles, $\varepsilon_{\text {glob }}=0,45 \%$ ). (b), (c) and (d) show the evolution of the local strain along paths \#1, \#2 and \#3. 


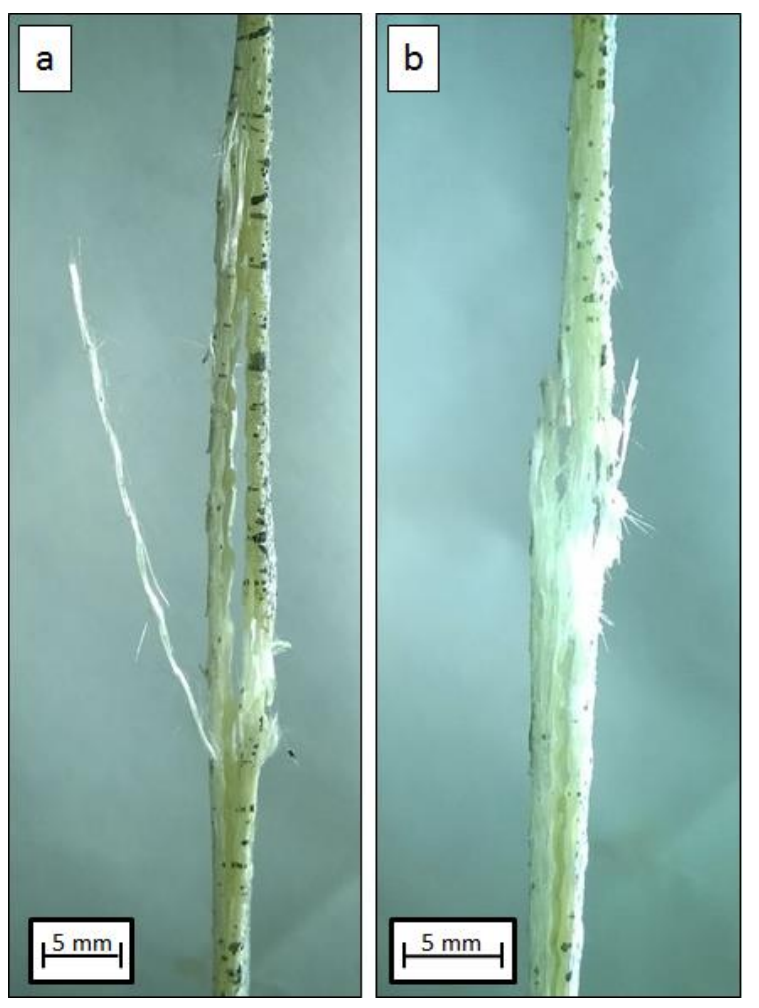

Figure 16 - Side view of LD samples with short fatigue life: $\sigma_{\max }=194 \mathrm{MPa}(\mathrm{a})$ and $\sigma_{\max }=$ 111 MPa (b) 


\begin{tabular}{|c|c|c|c|c|}
\hline & Global stress (MPa) & $\begin{array}{c}\text { Local maximum strain } \\
\text { LMS (\%) }\end{array}$ & $\begin{array}{c}\text { Global maximum strain } \\
\text { GMS (\%) }\end{array}$ & $\frac{L M S}{G M S}$ \\
\hline \multirow{9}{*}{ 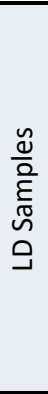 } & 193,80 & -- & -- & -- \\
\hline & 111,11 & $19,37 \%$ & $1,16 \%$ & 16,75 \\
\hline & 104,56 & $4,05 \%$ & $0,58 \%$ & 7,03 \\
\hline & 88,34 & $5,21 \%$ & $0,76 \%$ & 6,82 \\
\hline & 82,42 & $8,82 \%$ & $0,53 \%$ & 16,51 \\
\hline & 73,53 & $2,83 \%$ & $0,22 \%$ & 12,96 \\
\hline & 70,87 & $6,81 \%$ & $0,45 \%$ & 15,13 \\
\hline & 62,99 & -- & -- & -- \\
\hline & 46,30 & $1,19 \%$ & $0,22 \%$ & 5,54 \\
\hline \multirow{16}{*}{$\begin{array}{l}\frac{\tilde{d}}{0} \\
\stackrel{\varepsilon}{E} \\
\tilde{N} \\
0 \\
\mapsto\end{array}$} & 20,41 & -- & -- & -- \\
\hline & 20,33 & $3,35 \%$ & $0,17 \%$ & 20,19 \\
\hline & 19,46 & $4,10 \%$ & $0,19 \%$ & 22,16 \\
\hline & 20,62 & $4,00 \%$ & $0,20 \%$ & 20,41 \\
\hline & 20,16 & -- & -- & -- \\
\hline & 16,13 & -- & -- & -- \\
\hline & 15,59 & $4,38 \%$ & $0,13 \%$ & 32,94 \\
\hline & 15,94 & $3,06 \%$ & $0,15 \%$ & 19,84 \\
\hline & 16,13 & $3,75 \%$ & $0,15 \%$ & 24,64 \\
\hline & 15,33 & $6,83 \%$ & $0,23 \%$ & 29,18 \\
\hline & 14,82 & $4,50 \%$ & $0,16 \%$ & 28,13 \\
\hline & 14,94 & -- & -- & -- \\
\hline & 14,76 & $1,74 \%$ & $0,15 \%$ & 11,53 \\
\hline & 14,76 & $3,57 \%$ & $0,15 \%$ & 24,29 \\
\hline & 15,12 & $1,41 \%$ & $0,14 \%$ & 10,40 \\
\hline & 9,96 & -- & -- & -- \\
\hline \multirow{9}{*}{$\begin{array}{l}\frac{\tilde{\omega}}{0} \\
\stackrel{0}{\varepsilon} \\
\widetilde{n} \\
\varrho\end{array}$} & 220,59 & $15,91 \%$ & $1,39 \%$ & 11,45 \\
\hline & 190,84 & $10,96 \%$ & $1,20 \%$ & 9,11 \\
\hline & 163,64 & $5,39 \%$ & $1,01 \%$ & 5,34 \\
\hline & 163,64 & $7,20 \%$ & $1,02 \%$ & 7,09 \\
\hline & 151,52 & $16,14 \%$ & $0,93 \%$ & 17,33 \\
\hline & 132,08 & $4,49 \%$ & $0,79 \%$ & 5,66 \\
\hline & 127,38 & $2,54 \%$ & $0,67 \%$ & 3,79 \\
\hline & 116,91 & $5,84 \%$ & $0,73 \%$ & 8,05 \\
\hline & 112,78 & $2,90 \%$ & $0,62 \%$ & 4,70 \\
\hline
\end{tabular}

Table 2 - Maximum local and global strain

\section{Conclusion}

Static and fatigue tests were carried out on a GFRP with and without an induced out-of-plane mesoscopic defect. The orientation of this defect was also investigated.

The $0^{\circ}$ orientation defect (LD) showed that, despite very similar static behavior to that of the ND sample, the induced defect had a great influence on the fatigue behavior, even though the stresses investigated were lower. The use of digital image correlation allowed the observation of the number of cracks and the ratio of local strain over global strain was also much higher than on the healthy samples. It can thus be concluded that the presence of the defect with this orientation would make the sample more likely to undergo delamination.

However, the $90^{\circ}$ oriented defect (TD) showed the same influence of the presence of the defect on the behavior in static and in fatigue tests: it drastically decreased the mechanical characteristics.

Only two orientations, at a given buckle amplitude, were tested in this study. As they are the two extreme cases, it can be argued that the presence of this buckle defect in the composite, whatever 
the orientation, would have a non-negligible influence on the fatigue behavior. It would not even need to cover a large area as it would be a site where delamination would most likely be initiated.

More information about the damage undergone by the samples would be obtained with scanning electron microscopy on the areas where the out-of-plane defects induce a high local strain for example.

\section{Acknowledgment}

The authors wish to thank Centre-Val-de-Loire Region for its financial support in the project IDDEFORM. They also thank the team from the CERMEL and more particularly Mathieu Venin for his valuable help.

\section{References}

Allaoui S., Boisse P., Chatel S., Hamila S., Hivet G., Soulat D., Vidal-Salle E., 2011. Experimental and numerical analyses of textile reinforcement forming of a tetrahedral shape. Composites: Part A 42, 612-622

Allaoui S., Hivet G., Soulat D., Wendling A., Ouagne P., Chatel S., 2014. Experimental performing of highly double curved shapes with a case corner using an interlock reinforcement. Int. J. Mater. Form. 7, 155-165

Allaoui S., Cellard C., Hivet G., 2015a. Effect of inter-ply sliding on the quality of multilayer interlock dry fabric. Composites: Part A 68, 336-345

Allaoui S., Hivet G., Haddad M., Agogué R., Khellil K., Beauchene P., Aburra Z., Effect of the buckles mesoscopic defects on the composite properties. In ICCM-20. Copenhagen, July, 2015b.

Beaumont P.W.R., Sekine H., 2000. Physical modeling of engineering problems of composites and structures. Appl. Comp. Mat. 7, 13-37

Bloom L.D., Wang J., Potter K.D., 2013. Damage progression and defect sensitivity: an experimental study of representative wrinkles in tension. Composites: Part B 45, 449-458

Boisse P., Hamila N., Vidal-Sallé E., Dumont F., 2011. Simulation of wrinkling during textile composite reinforcement forming. Influence of tensile, in-plane shear and bending stiffness. Compos. Sci. Tech. 71, 683-692

Colombo C., Vergani L., 2014. Influence of the delamination on fatigue properties of a fiberglass composite. Comp. Struct. 107, 325-333

Demers C.E., 1998. Tension-tension axial fatigue of E-glass fiber-reinforced polymeric composites: tensile fatigue modulus. Constr. Build. Mat. 12(1), 51-58

Dyer K.P., Isaac D.H., 1998. Fatigue behavior of continuous glass fibre reinforced composites. Composites: Part B 29, 725-733

Epaarchchi J.A., 2006. Effects of static-fatigue (tension) on the tension-tension fatigue life of glass fibre reinforced plastic composites. Comp. Struct. 74, 419-425

Garcea S.C., Mavrogordato M.N., Scott A.E., Sinclair I., Spearing S.M., 2014. Fatigue micromechanism characterization in carbon fibre reinforced polymers using synchrotron radiation computed tomography. Comp. Sci. Tech. 99, 23-30

Garcea S.C., Sinclair I., Spearing S.M., 2015. In situ synchrotron tomographic evaluation of the effect of toughening strategies on fatigue micromechanisms in carbon fibre reinforced polymers. Comp. Sci. Tech. 109, 32-39 
Gatouillat S., Bareggi A., Vidal-Sallé E., Boisse P. Meso, 2013. modelling for composite preform shaping - simulation of the loss of cohesion of the woven fibre network. Composites: Part A 54, $135-144$

Hallander P., Akermo M., Mattei C., Petersson M., Nyman T., 2013. An experimental study of mechanisms behind wrinkle development during forming of composite laminates. Composites: Part A $50,54-64$

Hamila N., Boisse P., 2008. Simulations of textile composite reinforcement draping using a new semi discrete three node finite element. Composites: Part A 39, 999-1010

Härtel F., Middendorf P. Process parameters studies and comparison of different preform processes with NCF material. In proceeding of ICCM-19. Montreal, July, 2013

Helmy S., Hoa S.V., 2014. Tensile fatigue behavior of tapered glass fiber reinforced epoxy composites containing nanoclay. Comp. Sci. Tech. 102, 10-19

Hsiao H.M., Daniel I.M., 1996. Elastic properties of composites with fibre waviness. Composites: Part A 27, 931-941

Lightfoot J.S., Wisnom M., Potter K., 2013. Defects in woven preforms: formation mechanisms and the effects of laminate design and layup protocol. Composites: Part A 51, 99-107

Montesano J., Fawaz Z., Bougherara H., 2015. Non -destructive assessment of the fatigue strength and damage progression of satin woven fiber reinforced polymer matrix composites. Composites: Part B 71, 122-130

Naderi M., Khonsari M.M., 2012. Thermodynamic analysis of fatigue failure in a composite laminate. Mech. of Mat. 46, 113-122

Piggott M.R., 1995. The effect of fiber waviness on the mechanical properties of unidirectional fibre composite: a review. Comp. Sci. \& Tech. 53, 201-205

Phoenix S.L., 2000. Modeling the statistical lifetime of glass fiber/polymer matrix composites in tension. Comp. Struct. 48, 19-29

Potluri P., Sharma S., Ramgulam R., 2001. Comprehensive drape modeling for molding 3D textile preforms. Composites: Part A 32, 1415-1424

Potter K., Khan B., Wisnom M., Bell T., Stevens J., 2008. Variability, fibre waviness and misalignment in the determination of the properties of composite materials and structures. Composites: Part $A$ 39, 1343-1354

Prodromou A.G.,Chen K., 1997. On the relationship between shear angle and wrinkling of textile composite preforms. Composites: Part A 28, 491-503

Reifsnider K.L. Damage and damage mechanics In: Raifsnider KL, editor. Fatigue of composite materials. Amsterdam: Elsevier; 1990

Reis P.N.B., Ferreira J.A.M., Antunes F.V., Richardson M.O.W., 2009. Effect of interlayer delamination on mechanical behavior of carbon/epoxy laminates. J. of Comp. Mat. 43, 2609-2621

Sharma S.B., Sutcliffe M.P.F., Chang S.H., 2003. Characterization of material properties for draping of dry woven composite material. Composites: Part A 34, 1167-1175

Ten Thije R.H.W., Akkerman R., Huétink J., 2007. Large deformation simulation of anisotropic material using an updated lagrangian finite element method. Comp. Meth. In App. Mech. \& Eng. $196,3141-3150$

Thawre M.M., Verma K.K., Jagannathan N., Peshwe D.R., Paretkar R.K., 2016. Effect of Ply-drop on fatigue life of carbon fiber composite under a fighter aircraft spectrum load sequence. Comp. Part $B$ $86,120-125$ 
Wang J., Paton R., Page J.R., 1999. The draping of woven fabric preforms and prepregs for production of polymer composite components. Composites: Part A 30, 757-765

Wang J., Potter K., Hazra K., Wisnom W., 2012. Experimental fabrication and characterization of out-of-plane fiber waviness in continuous fiber-reinforced composites. Jour. of Comp. Mat. 46, 2041:2053

Wilems A., Lomov S., Verpoest I., Vandepitte D., Harrison P., Yu W. Forming, 2008. Simulation of a thermoplastic commingled woven textile on a double dome. Int.Jour. of Mat. Form. 1, 965-968 